\title{
Sciences sociales et populisme
}

Social Science and Populism

Ciencias sociales y populismo

\section{Derek Robbins}

Traducteur : Claire Ducournau et Karim Hammou

\section{Q OpenEdition \\ Journals}

\section{Édition électronique}

URL : http://journals.openedition.org/bssg/147

DOI : $10.4000 /$ bssg. 147

ISSN : 2490-9424

\section{Éditeur}

Presses universitaires de Vincennes

\section{Référence électronique}

Derek Robbins, « Sciences sociales et populisme », Biens Symboliques / Symbolic Goods [En ligne], 1। 2017, mis en ligne le 15 octobre 2017, consulté le 04 mars 2021. URL : http:// journals.openedition.org/bssg/147 ; DOI : https://doi.org/10.4000/bssg.147 

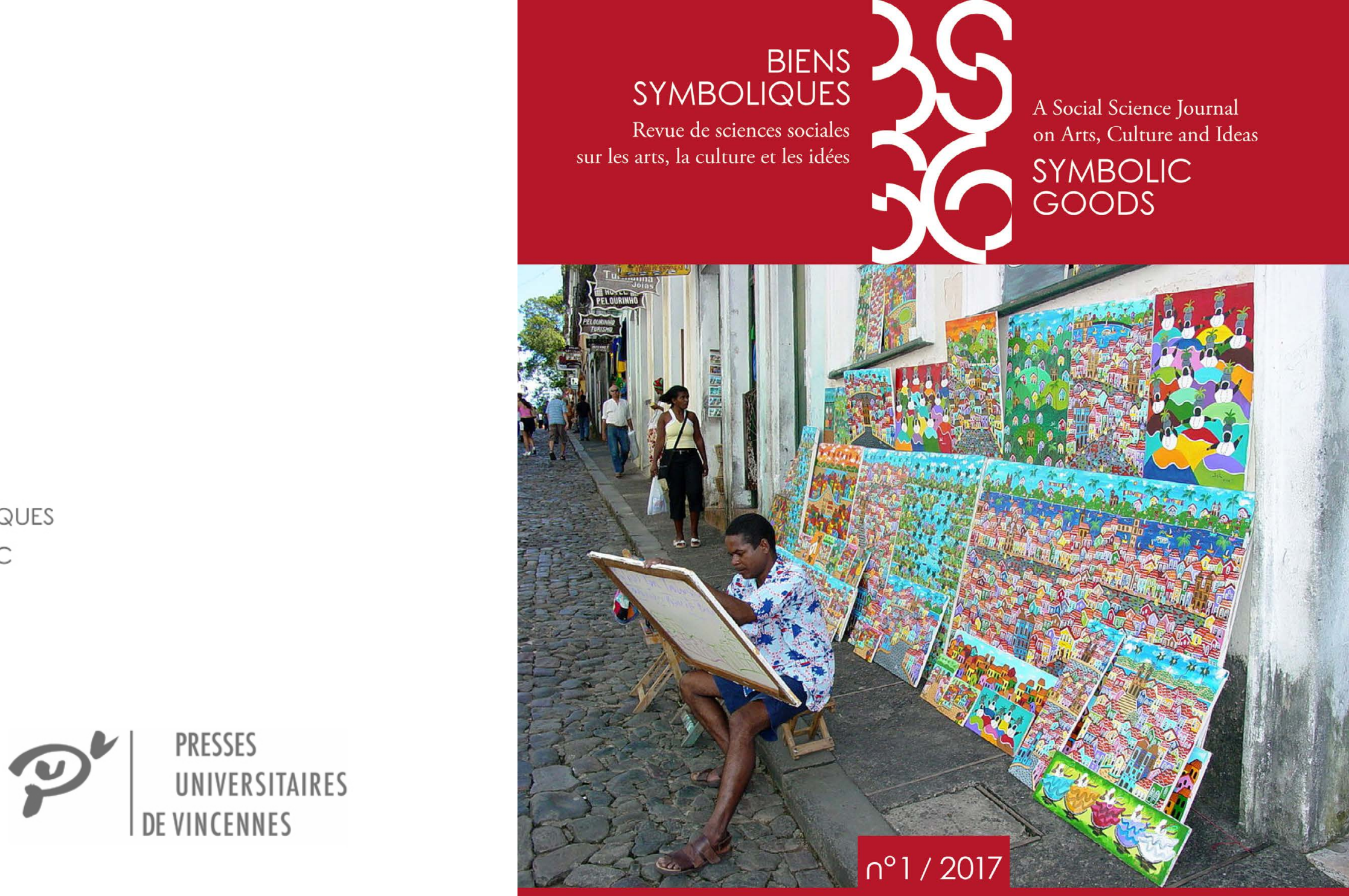

\section{Artistes ordinaires \\ Ordinary Artists}




\section{Sciences sociales et populisme}

Derek Robbins

traduction | translation

Claire Ducournau et Karim Hammou

La publication de La Reproductionen 1970 estl'aboutissement de plus de cinq ans d'approfondissement d'une recherche entreprise au sein du Centre de sociologie européenne, au début des années 1960, par une équipe de chercheur·e·s dirigée par Pierre Bourdieu et Jean-Claude Passeron, et qui avait déjà abouti à la publication des Héritiers en 1964. Séparément ou ensemble, Bourdieu et Passeron ont écrit des articles qui anticipaient les événements de Mai 1968. Les contestations étudiantes vis-à-vis des conditions universitaires, associées à un mouvement syndical plus vaste, avaient alors débouché sur le départ de de Gaulle du pouvoir. Ces chercheurs avançaient que l'enseignement des sciences sociales et de la philosophie dans les universités françaises présupposait une familiarité avec les valeurs culturelles traditionnelles et dominantes, ce qui favorisait la réussite des étudiant·e.s qui possédaient déjà à leur entrée dans les études supérieures le capital culturel nécessaire. Cette imposition arbitraire d'une seule culture occultait l'existence de cultures populaires valables, et pérennisait l'échec des étudiant·ess qui n'étaient familier·e.s que de cultures différentes. C'est en association avec Jean-Claude Chamboredon que Bourdieu et Passeron publient, en 1968, Le Métier de sociologue, ouvrage pensé comme un manuel destiné à aider de jeunes chercheur·e.s à surmonter leur désavantage culturel, en élaborant et en menant des projets de recherche qui s'appuieraient sur leurs expériences passées plutôt que sur des procédures canoniques prédéfinies. Autrement dit, il s'agissait d'éliminer une ségrégation tacite entre la recherche en sciences sociales et l'expérience populaire.

En 1966, Passeron se rendit à l'Université de Nantes, où il fonda le département de sociologie. Après les événements de Mai 1968, la rupture fut consommée entre Aron et Bourdieu, rupture sur laquelle Aron est revenu avec acrimonie dans ses Mémoires (Aron 1983). Après l'élection d'Aron au Collège de France en 1970, Bourdieu prit la direction du Centre de sociologie européenne. Pendant ce temps, Passeron avait quitté Nantes pour devenir l'un des premiers membres de l'équipe du centre universitaire expérimental établià Vincennes par le décret gouvernemental du 7 décembre 1968. Ce centre était pensé comme une réponse directe aux problèmes du système universitaire révélés par les événements de Mai. La loi d'orientation introduite à la suite de ces événements prévoyait que les universités deviendraient pluridisciplinaires, et associeraient autant que possible les disciplines artistiques et littéraires aux disciplines scientifiques et technologiques, tout en maintenant une orientation dominante de type vocationnel (Debeauvais 1976 : 15-18). 
Il est important de rappeler ces circonstances, qui sont celles dans lesquelles Passeron a travaillé comme directeur du département de sociologie de 1968 à 1977. Se remémorant ce contexte, dont il était partie prenante, Jacques Rancière a écrit que « cette université, créée de toutes pièces pendant l'été 1968, était censée donner aux étudiants rebelles la nouveauté qu'ils espéraient » (Rancière 2011:213). Vincennes représentait, en d'autres termes, une initiative institutionnelle supposée combler le fossé qui séparait le populisme de la science. Et pour ce qui concerne le travail de Passeron, ce contexte impliquait le défi de tirer les conséquences pratiques des conclusions des Héritiers et de La Reproduction de façon à offrir un enseignement pluridisciplinaire à des étudiant $\cdot e \cdot s$ issu.e.s de parcours non traditionnels, de façon à les préparer à travailler dans le monde moderne. II n'est pas surprenant que deux de ses sujets de prédilection deviennent ensuite d'une part, la nature des relations entre cultures populaire et savante, et d'autre part, la nature des distinctions disciplinaires dans un contexte d'action pluridisciplinaire.

Passeron écrivit relativement peu durant les années 1970, mais sa présentation de la traduction du livre The Uses of Literacy de Richard Hoggart, intitulée La Culture du pauvre (Hoggart 1970a), témoignait déjà de son intérêt pour un mode d'analyse scientifique des cultures populaires dénué de condescendance. D'origine ouvrière, Hoggart était un étudiant en littérature anglaise dépourvu de formation sociologique. Son livre était une tentative " de description des relations et des attitudes caractéristiques de la classe ouvrière " (Hoggart 1957 : 10), reposant « dans une large mesure sur l'expérience personnelle » (ibid.). II n'avait pas « la prétention d'avoir les caractéristiques scientifiques d'une enquête sociologique » (ibid.). Toutefois, Hoggart reconnaissait qu'il y avait un danger à généraliser depuis une expérience limitée. Par conséquent, il précisait dans sa préface qu'il avait inclus " certains résultats auxquels aboutissent les sociologues là où ils semblaient nécessaires » et qu'il avait également « mentionné à une ou deux occasions l'opinion différente d'autres personnes ayant connu des expériences similaires aux miennes » (ibid.). Hoggart acceptait donc une distinction conceptuelle entre le récit d'expérience et la distanciation scientifique. En revanche, la traduction française introduit une nuance qui ne se trouve pas dans l'original lorsqu'elle traduit la fin de cette phrase de la façon suivante : « j'ai aussi cité quelques opinions d'écrivains ou de sociologues d'origine populaire dont les conclusions contredisent parfois les miennes » (Hoggart 1970a: 29). La traduction introduit la possibilité que la recherche sociologique elle-même puisse être relative, ce qui n'était pas (directement) envisagé par Hoggart.

Un même caractère expérimental rapproche le centre universitaire de Vincennes (qui devint formellement I'Université Paris 8 en janvier 1971) et les trente nouvelles écoles polytechniques mises en place par le gouvernement travailliste du Royaume-Uni au début des années 1970. Alors que, pour le gouvernement français, l'expérience pourrait se voir déployée dans l'ensemble du système universitaire, le gouvernement britannique réagissait pour sa part aux demandes des étudiant·e.s défavorisé·e.s et aux besoins des employeurs en mettant en place de nouvelles institutions qui fonctionneraient parallèlement aux universités traditionnelles, 
et en opposition à ces dernières. Implicitement, ces nouvelles institutions pouvaient être des « universités populaires» (voir Robinson 1968) mais ne devaient pas empiéter sur l'éducation universitaire «véritable », qui se poursuivait ailleurs. II n'y avait aucun engagement explicite en faveur de la pluridisciplinarité. Y prévalait plutôt la transmission d'un savoir « appliqué », qui reposait sur le caractère vocationnel de ces institutions de seconde zone, sans qu'elles viennent altérer les structures de savoir traditionnelles. C'est dans ce contexte que certains diplômes en «études culturelles » furent validés dans les années 1980. Ils voyaient généralement le jour dans les départements de sociologie, mais ils offraient un cadre dans lequel sociologues, historien.e.s et critiques littéraires pouvaient collaborer. Des enseignant $\cdot e \cdot s$ d'histoire et de littérature y adoptaient une orientation conceptuelle commune qui s'adossait à une sociologie de la culture implicite. Ils attirèrent des équipes enseignantes et des étudiant·e.s parce qu'ils manifestaient de l'intérêt pour la culture ouvrière et l'histoire populaire ou orale, dans des institutions qui aspiraient encore à être des universités « populaires ».

Ces Cultural Studies se développèrent dans les années 1980. Leur caractère sociologique sous-jacent donna aux enseignements leur cohérence sans qu'il semble nécessaire de revenir sur les épistémologies propres aux analyses historiques ou littéraires, ou aux relations entre la recherche sociologique et les pratiques culturelles qui étaient prises pour objet dans ces enquêtes. Jean-Claude Passeron quitta Vincennes en 1977 et, dans le même mouvement, abandonna l'investissement intense que supposait la mise en place d'innovations pédagogiques, telles qu'elles étaient préconisées dans le décret gouvernemental initial. II semble juste de suggérer que Passeron prolongea, dans ses propres recherches et dans l'encadrement des recherches de ses étudiant·e.s, la pensée qu'il avait mise en œuvre auprès des étudiant·e.s de premier cycle de Vincennes. De 1977 à 1981, Passeron était en détachement auprès du Centre national de la recherche scientifique (CNRS). II y mit en place le GIDES, Groupe inter-universitaire de documentation et d'enquêtes sociologiques de recherche et, en 1982, devint directeur d'études à l'École des hautes études en sciences sociales (EHESS).

Pendant cette période, il prépara un doctorat d'État à I'Université de Nantes, doctorat qu'il publia en 1980 sous le titre Les Mots de la sociologie. La forme de cette thèse est significative : une série d'essais issus de séminaires de recherche préparés pour des étudiant·e·s en formation à la recherche. Passeron percevait ce texte comme un aboutissement du projet inachevé dont Le Métier de sociologue ne devait être que le premier volume (Bourdieu, Chamboredon, Passeron 1968). L'intention de Passeron était de montrer que la recherche sociologique ne s'effectuait pas au sein de systèmes conceptuels préalables, mais constituait plutôt un type de discours particulier s'efforçant de rendre compte des phénomènes étudiés. II affirmait que le langage sociologique trouve son sens en relation aux situations sociales concrètes qu'il cherche à analyser, tandis que le langage philosophique est auto-référentiel. C'était cette conviction qui allait marquer le développement de la pensée de Passeron, aussi bien en ce qui concerne les relations entre langage ordinaire et langage sociologique, qu'en ce qui 
concerne les fondements des distinctions entre disciplines universitaires.

Passeron acheva Les Mots de la sociologie peu après la publication de La Distinction par Pierre Bourdieu (1979). La Distinction était un livre qui irrita nombre d'anciens collaborateurs de Bourdieu. Claude Grignon, en particulier, affirma que Bourdieu méprisait la classe ouvrière ou la culture populaire en cherchant à l'analyser scientifiquement à l'aune des valeurs propres à la culture dominante. II y avait aussi le sentiment que Bourdieu avait trahi, socialement, la culture dominée en acceptant une chaire de sociologie au Collège de France en 1981-1982. La position de Passeron était plutôt que Bourdieu s'était autorisé à développer un système conceptuel d'explication a priori - habitus, champ, capital culturel - qu'il appliquait à une diversité de situations sociales, au lieu de laisser chaque nouvelle situation susciter de nouveaux outils conceptuels.

Grignon et Passeron ont débattu de ces questions dans un échange qui prit la forme d'un séminaire de recherche organisé à Marseille en 1982. Cet échange fut tout d'abord publié en 1982 comme document de travail sous le titre Sociologie de la culture et sociologie des cultures populaires (Grignon \& Passeron 1982). II fut réédité sous le titre « À propos des cultures populaires » dans le premier numéro de la revue Enquête en 1985, et finalement publié par les éditions du Seuil/Gallimard en 1989 sous le titre Le Savant et le Populaire. Misérabilisme et populisme en sociologie et en littérature (Grignon \& Passeron 1989). Ainsi, tout au long des années 1980 , ce texte fut un point de référence, qui déclinait les conséquences de la conception passeronienne du « raisonnement sociologique » pour les recherches sur les cultures et la littérature populaires. Passeron déployait ses efforts pour conserver une dimension épistémologique dans l'enquête en sciences sociales, en cherchant à résister d'une part, à la tendance à isoler l'épistémologie de la pratique et, d'autre part, à réduire les sciences sociales au rôle de pourvoyeuses d'outils sans réflexivité.

L'interdisciplinarité a connu une évolution différente dans les arts et les sciences sociales britanniques depuis 1980. En 1992, le gouvernement conservateur abolit la distinction institutionnelle entre les universités et les écoles polytechniques. La fin de cette différentiation idéologique entre deux types d'institutions contraignit les écoles polytechniques, devenues « nouvelles universités 》 ou " universités 1992 ", à une soumission culturelle vis-à-vis de l'ethos des université dominantes, dites du "groupe de Russell ". Les Cultural Studies disparurent en tant que mécanisme de légitimation des cultures populaires. À partir du début des années 1990, l'organisation des curricula dans l'enseignement supérieur au Royaume-Uni est en partie modelée par la façon dont la recherche est financée et évaluée à l'échelle nationale. Les agences de financement les plus importantes, aussi bien pour les équipes de recherche que pour les bourses de recherche destinées aux étudiants, sont le Conseil de la recherche économique et sociale (ESRC) et le Comité de la recherche dans les arts et les humanités (AHRB), renommé Conseil de la recherche dans les arts et les humanités (AHRC) en 1997. Bien que chacune de ces deux agences se donne pour objectif de favoriser des projets et des formations « interdisciplinaires », elles s'appuient sur 
des comités formés dans un cadre disciplinaire traditionnel, ce qui dote les Cultural Studies d'une existence ambivalente aux yeux des deux agences.

Cette brève histoire de quelques aspects de l'enseignement supérieur français et britannique éclaire le malaise sociopolitique actuel dans ces deux pays face à la montée du populisme et à la perte de confiance vis-à-vis des experts scientifiques. Il serait possible de remédier à ces problèmes en prêtant une attention renouvelée à l'effort de réconciliation discuté dans Le Savant et le Populaire, dont la marginalisation a contribué à développer la situation actuelle.

Derek Robbins School of Social Sciences, University of East London https://www.uel.ac.uk/schools/social-sciences

\section{Références bibliographiques}

Aron Raymond (1983). Mémoires. Paris, Julliard.

BAKHTINE Mikhaïl (1970). L'CEuvre de François Rabelais et la culture populaire au Moyen Âge et sous la Renaissance. Paris, Gallimard.

BECKER Howard (1988). Les Mondes de l'art. Traduit de l'anglais par Jeanne Bouniort. Paris, Flammarion.

Bellavance Guy, Boivin Micheline, SanterRe Lise (dir.) (2000). Démocratisation de la culture ou démocratie culturelle ? Deux logiques d'action publique. Québec, Éditions de l'IQRC.

Bols Géraldine (2008). "Le consentement à la domination littéraire. Degrés et diversité de ses formes chez les écrivains "les moins reconnus" de l'univers littéraire ». Tracés, $14:$ 55-76.

Bourdieu Pierre (1979). La Distinction. Critique sociale du jugement. Paris, Minuit.

BouRDIEU Pierre (1984). Questions de sociologie. Paris, Minuit.

BouRdiEU Pierre (1988). « Entretien recueilli par Beate Krais ». In BouRdieU

Pierre, Chamboredon Jean-Claude, PAsseron Jean-Claude, Le Métier de sociologue. Préalables épistémologiques. Paris, Éditions de l'EHESS (cinquième édition).

Bourdieu Pierre (1989). La Noblesse d'État. Paris, Minuit.

BOURDIEU Pierre (1993). "Les contradictions de l'héritage ». In Bourdieu Pierre (dir.), La Misère du monde. Paris, Seuil : 711-718.

Bourdieu Pierre (1998) [1992]. Les Règles de l'art. Genèse et structure du champ littéraire. Paris, Seuil.

BouRdieu Pierre (1998). La Domination masculine. Paris, Seuil.

Bourdieu Pierre (2003) [1997]. Méditations pascaliennes. Paris, Seuil.

Bourdieu Pierre, Chamboredon Jean-Claude, Passeron Jean-Claude (1968). Le Métier de sociologue. Paris, Mouton.

Bourdieu Pierre \& Passeron Jean-Claude (1964). Les Héritiers. Les étudiants et la culture. Paris, Minuit.

BOURDIEU Pierre \& PASSERON Jean-Claude (1970). La Reproduction. Éléments pour une théorie du système d'enseignement. Paris, Minuit.

BOURDIEU Pierre \& WACQUANT Loïc (2014). Invitation à la sociologie réflexive. Paris, Seuil.

BOUTIER Jean (2008). "Quelques réflexions rétrospectives sur les histoires de la "culture populaire" ». Journée d'étude "Le Savant et le Populaire, 1989-2008. Retour sur un débat en suspens ". SHADYC, EHESS Marseille (non publié).

BOUVERESSE Jacques (2008). " Le besoin de croyance et le besoin de vérité ». Agone, 38-39: 281-306.

BURKE Peter (1978). Popular Culture in Early Modern Europe. Londres, Temple Smith.

Buscatto Marie (2014). Sociologies du genre. Paris, Armand Colin.

Busino Giovanni (2006). "Entretien avec Dominique Schnapper ». Revue européenne des sciences sociales, XLIV(135). [En ligne] http://ress. revues.org/271 [consulté le 12 octobre 2016].

Casanova Pascale (2008) [1999]. La République mondiale des lettres. Paris, Seuil.

CHAPOULIE Jean-Michel (1991). « La seconde fondation de la sociologie française, les États-Unis et la classe ouvrière ». Revue française de sociologie $32(3)$ : 321-364

CHARTIER Roger (2001). "Culture écrite et littérature à l'âge moderne 》. Annales. Histoire, Sciences sociales, 56(4) : 783-802. 
COHEN Déborah (2010). La Nature du peuple. Les formes de l'imaginaire social (XVIII/XXI siècles). Seyssel, Champ Vallon.

ColleCtIF (1988). « Histoire et sciences sociales. Un tournant critique ? ». Annales ESC, 2 : 291-293.

Collectif Révoltes logiques (1984). L'Empire du sociologue. Paris, La Découverte.

Collovald Annie (1988). "Identité(s) stratégiques(s) ", Actes de la recherche en sciences sociales, $73: 29-40$.

ConnelL Raewyn (1995). Masculinities. Cambridge, Polity Press.

CoRnu Tanguy (2008). « L'ambiguïté du concept de domination symbolique dans Le Savant et le Populaire ". Journée d'étude "Le Savant et le Populaire, 1989-2008. Retour sur un débat en suspens ". SHADYC, EHESS Marseille (non publié).

CoULANGEON Philippe \& DUVAL Julien (2013). Trente ans après La Distinction de Pierre Bourdieu. Paris, La Découverte.

CoUlANGEON, Philippe \& DUVAL Julien (2013). «Introduction ». In EID. (dir.), Trente ans après La Distinction de Pierre Bourdieu. Paris, La Découverte. Daudet Alphonse (1868). Le Petit Chose. Paris, Pierre-Jules Hetzel.

DebeauvaIs Michel (1976). L'Université ouverte : les dossiers de Vincennes. Grenoble, Presses Universitaires de Grenoble.

Dragomir Lucia (2011). «L'Union des écrivains. Un modèle institutionnel et ses limites ». Vingtième siècle, $109: 59-70$.

Ducournau Claire (2017). " Les deux (ou trois) carrières de Richard Hoggart. De la fondation des cultural studies aux appropriations de la sociologie française ". Revue d'anthropologie des connaissances, 11(3) : 263-282.

DUMONT Fabienne \& SoFIO Séverine (2007). « Esquisse d'une épistémologie de la théorisation féministe en art ». Cahiers du genre, 43 17-43.

DuVAL Julien (2010). " Distinction studies ". Actes de la recherche en sciences sociales, 181-182: 146-156.

ELIAS Norbert (1991). La Société des individus. Traduit de l'allemand par Jeanna Etoré. Paris, Fayard.

FABIANI Jean-Louis (dir.) (2001). Le Goût de l'enquête. Pour Jean-Claude Passeron. Paris, L'Harmattan.
FosSÉ-POLIAK Claude (2006). Aux frontières du champ littéraire. Sociologie des écrivains amateurs. Paris, Économica.

FoucAult Michel (1973). Moi, Pierre Rivière ayant égorgé ma mère, ma sœur et mon frère... Paris, Gallimard/Julliard.

FoucAult Michel (1994). Dits et écrits, t. 1 et 2. Paris, Gallimard.

GaBORIAU Philippe (1995). Le Tour de France et le vélo. Histoire sociale d'une épopée contemporaine. Paris, L'Harmattan.

GabORIAU Philippe (2003). Les Spectacles sportifs. Grandeurs et décadences. Paris, L'Harmattan.

GinzBURG Carlo (1980) [1976]. Le Fromage et les vers. L'univers d'un meunier $d u x v l^{e}$ siècle [Il formaggio e $i$ vermi. II cosmo di un mugnaio del Cinquecento, Turin, Einaudi]. Traduit de l'italien par Monique Aymard. Paris, Flammarion.

Grenier Jean-Yves, Grignon Claude, Menger Pierre-Michel (dir.) (2001). Le Modèle et le récit. Paris, Maison des Sciences de l'Homme.

Grignon Claude (1996). " Le savant et le lettré, ou l'examen d'une désillusion ", Revue européenne des sciences sociales, 103 : 81-98.

GriGNon Claude (2001). " La formalisation et les sciences du récit, le cas de la sociologie ». In Grenier Jean-Yves, Grignon Claude, Menger Pierre-Michel (dir.), Le Modèle et le récit. Paris, Maison des Sciences de l'Homme : 7-43.

Grignon Claude \& Kordon Claude (dir.) (2009). Sciences de l'homme et sciences de la nature, essais d'épistémologie comparée. Paris, Maison des Sciences de l'Homme.

GriGnOn Claude \& PASSERON Jean-Claude (1982). Sociologie de la culture et sociologie des cultures populaires. Paris, Documents du GIDES, 4.

Grignon Claude \& PAsseron Jean-Claude (1985). Enquête. Cahiers du CERCOM, 1 (« À propos des cultures populaires »). [En ligne] https:// enquete.reveues.org/2 [consulté le 26 juin 2017].

GriGnon Claude \& PASSERON Jean-Claude (2015) [1989]. Le Savant et le Populaire. Misérabilisme et populisme en sociologie et en littérature. Paris, Seuil, «Points 》[1 $1^{\text {re }}$ éd. Gallimard/Seuil, « Hautes études 》]. En espagnol : Grignon Claude \& PASSERON Jean-Claude (1991). Lo culto y lo popular : miserabilismo y populismo en sociologia y en literatura. Traduction de María Sonderéguer. Buenos Aires, Ediciones Nueva Vision; 
Grignon Claude \& PASSERON Jean-Claude (1992). Lo culto y lo popular : miserabilismo y populismo en sociologia y en literatura. Traduction de Fernando Alvarez-Uria et Julia Varela. Madrid, Las Ediciones de La Piqueta.

Grignon Claude, Collovald Annie, Pudal Bernard, Sawicki Frédéric (1991). « Un savant et le populaire. Entretien avec Claude Grignon ». Politix, $13: 35-42$

GRUEL Louis (2004). La Rébellion de 68. Une relecture sociologique. Rennes, Presses Universitaires de Rennes.

Guillaumin Colette (2002) [1972]. L'Idéologie raciste. Paris, Gallimard. HaLL Stuart \& JeFFERSON Tony (dir.) (1976). Resistance through Rituals : Youth Subcultures in Post-War Britain. Londres, Hutchinson.

Hammou Karim (2008). «Penser le pouvoir avec Le Savant et le Populaire». Journée d'étude "Le Savant et le Populaire, 1989-2008. Retour sur un débat en suspens ". SHADYC, EHESS Marseille (non publié).

HeINICH Nathalie (2000) [1991]. Etre écrivain. Paris, La Découverte.

HOGGART Richard (1970a). La Culture du pauvre. Étude sur le style de vie des classes populaires en Angleterre. Traduit de l'anglais par Françoise Garcia, Jean-Claude Garcia et Jean-Claude Passeron, présentation et index de Jean-Claude Passeron (titre original The Uses of Literacy : Aspects of Working Class Life). Paris, Minuit.

HogGART Richard (1970b). Speaking to Each Other, vol. 1. Londres, Chatto et Windus.

HogGaRT Richard (2013) [1991]. 33 Newport Street. Autobiographie d'un intellectuel issu des classes populaires anglaises. Traduit de l'anglais par Christiane Grignon \& Claude Grignon avec la collaboration de Christopher Todd, présentation de Claude Grignon. Paris, Seuil, « Points »

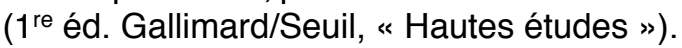

KaliFa Dominique (2005). "Les historiens français et le "populaire" ». Hermès, $42: 54-59$.

KRÉFA Abir (2013). « La quête de l'autonomie littéraire en contexte autoritaire : le cas des écrivains tunisiens ». Sociologie, $4: 395-411$.

KRÉFA Abir (2013). Activités littéraires et rapports sociaux de sexe : le cas des écrivains tunisiens (thèse de doctorat en sociologie). Lyon, Universite Lyon 2.
KRÉFA Abir (2014). « Entre injonctions à dire et à taire le corps : les voies étroites de la reconnaissance littéraire pour les écrivaines tunisiennes 》. Ethnologie française, 44(4) : 631-642.

LAGRAVE Rose-Marie (1980). Le Village romanesque. Le Paradou, Actes Sud, « Espace-temps ».

LAGRAVE Rose-Marie (1988). "Mensonge romanesque et vérité des romanciers. Une relecture du Village Romanesque ». Études Rurales, $109: 55-73$.

LAGRAVE Rose-Marie (2009). "Filiations intellectuelles et espérance sociale. Figure et œuvre de Placide Rambaud ». Études rurales, 183 : 51-66.

LAGRAVE Rose-Marie (2010). "Se ressaisir 》. Genre, Sexualité \& Société, 4 : 1-17. [En ligne] http://gss.revues.org

LAHIRE Bernard (2004). La Culture des individus : dissonances culturelles et distinction de soi. Paris, La Découverte.

LAHIRE Bernard (2008). La Raison scolaire. École et pratiques d'écriture, entre savoir et pouvoir. Rennes, Presses Universitaires de Rennes.

LahIRE Bernard (2012). Monde pluriel. Penser l'unité des sciences sociales. Paris, La Découverte.

LAMONT Michèle (1995). La Morale et l'argent : les valeurs des cadres en France et aux États-Unis. Paris, Métailié.

LAMONT Michèle (2013). "En quoi Bourdieu a-t-il été utile à notre réflexion ? Le cas des États-Unis ». In Coulangeon Philippe \& DuvaL Julien (dir.), Trente ans après La Distinction de Pierre Bourdieu. Paris, La Découverte : 59-68.

Levi Giovanni (1989). Le Pouvoir au village. Histoire d'un exorciste dans le Piémont du XVII siècle. Paris, Gallimard.

LINHART Robert (1981). L'Établi. Paris, Minuit.

MACKENZIE Caroline (2012). "Agency, un mot, un engagement 》. Rives méditerranéennes, 41(1). [En ligne] http://rives.revues.org/4139 [consulté le 11 mars 2017].

MatHIEU Nicole-Claude (1991). L'Anatomie politique. Paris, Côté-Femmes. MAUgeR Gérard (1991). "Enquêter en milieu populaire 》. Genèses, 6 : 125-143.

MAUGER Gérard (2005). " Un apprentissage tardif du métier de sociologue ». In MAUGER Gérard (dir.), Rencontres avec Pierre Bourdieu. Bellecombe-en-Bauges, Le Croquant : 239-257. 
MAuger Gérard (2006a). «Sur la violence symbolique ». In MüLleR HansPeter \& Sintomer Yves (dir.). Pierre Bourdieu, théorie et pratique. Paris, La Découverte : 84-100.

MAUGER Gérard (2006b). Les Bandes, le milieu et la bohème populaire. Études de sociologie de la déviance des jeunes des classes populaires (1975-2005). Paris, Belin.

MAUGER Gérard (2013). « Bourdieu et les classes populaires. L'ambivalence des cultures dominées ». In CoulangEON Philippe \& DUVAL Julien (dir.), Trente ans après La Distinction de Pierre Bourdieu. Paris, La Découverte : 243-254

MAUGER Gérard (2014). « Domination ». Le Lexique socius. [En ligne] http:// ressources-socius.info/index.php/lexique/21-lexique/154-domination [consulté le 14 janvier 2017].

MAUGER Gérard \& Fossé Claude (1977). La Vie buissonnière. Marginalité petite-bourgeoise et marginalité populaire. Paris, Maspero.

MAUgeR Gérard \& Fossé-PoliaK Claude (1985). « Choix politiques et choix de recherches. Essai d'auto-socio-analyse (1973-1984) ». Cahiers « Jeunesses et Sociétés », 3-4-5: 27-121.

MengeR Pierre-Michel (2009). Le Travail créateur. S'accomplir dans l'incertain. Paris, Gallimard/Seuil, « Hautes études ».

MorRIson Toni (1990). Playing in the Dark: Whiteness and The Literary Imagination. New York, Vintage Books.

Moulin Raymonde (1971). «La Culture du pauvre. À propos du livre de Richard Hoggart ». Revue française de sociologie, 12(2) : 255-258.

Moulin Raymonde (1992). L'Artiste, l'institution et le marché. Paris, Flammarion.

Moulin Raymonde(dir.) (1986). Sociologie del'art. Paris, La Documentation française.

Moulin Raymonde, PAsseron Jean-Claude, PAsquier Dominique, PortoVAsquez Fernando (1985). Les Artistes, essai de morphologie sociale. Paris, La Documentation Française.

NAUDIER Delphine \& ROLLET Brigitte (2007). Genre et légitimité culturelle Quelle reconnaissance pour les femmes ?. Paris, L'Harmattan.

NAVEL Georges (1945). Travaux. Paris, Gallimard.

NeVEU Érik (1999). “ Pour en finir avec l'enfantisme. Retours sur enquêtes ». Réseaux, 92-93:175-201.
Neveu Erik (2008). « Les voyages des cultural studies ». L'Homme, 187$188: 315-341$.

NoIRIEL Gérard (1988). Le Creuset français. Histoire de l'immigration $\left(X I X^{e}-X X^{e}\right.$ siècle). Paris, Seuil.

OlivieR DE SARDAN Jean-Pierre (2008). La Rigueur du qualitatif. Les contraintes empiriques de l'interprétation socio-anthropologique. Louvain Bruylant Academia.

PARETo Vilfredo (1917). Traité de sociologie générale. Traduit de l'italien par Pierre Boven. Lausanne, Payot.

PAsquali Paul \& Schwartz Olivier (2016). « La Culture du pauvre : un classique revisité. Hoggart, Les classes populaires et la mobilité sociale ». Politix, 114 : 21-45.

Pasqual Paul (2014). Passer les frontières sociales. Comment les " filières d'élite » entrouvrent leurs portes. Paris, Fayard.

PAsquier Dominique (1989). La Culture des sentiments. L'expérience télévisuelle des adolescents. Paris, Éditions de la MSH.

PASQUIER Dominique (2005). " La "culture populaire" à l'épreuve des débats sociologiques ». Hermès, 42 : 60-69.

PASSERON Jean-Claude (2006) [1991]. Le Raisonnement sociologique. Un espace non poppérien de l'argumentation. Paris, Albin Michel, nouvelle édition revue et augmentée (première édition Paris, Nathan).

Passeron Jean-Claude \& Pedler Emmanuel (1991). Le Temps donné aux tableaux. Compte rendu d'une enquête au musée Granet. Marseille, Imerec.

PAsseron Jean-Claude \& GRUMBACH Michel (dir.) (1985). L'CEil à la page enquête sur les images et les bibliothèques. Paris, Bibliothèque publique d'information, Service des études et de la recherche.

PASSERON Jean-Claude (dir.) (1999). Richard Hoggart en France. Paris, Bibliothèque publique d'information.

Pedler Emmanuel (2010). « Les sociologies de la musique de Max Weber et Georg Simmel. Une théorie relationnelle des pratiques musiciennes ». L’Année sociologique, 60(2) : 305-330.

Pedler Emmanuel (2016). L'Esprit des lieux. Paris, Éditions de l'EHESS. Pedler Emmanuel \& Bourbonnaud David (2002a). « L'offre du festival "in" d'Avignon : effet d'imposition ou stimulation culturelle ? ". Actes du colloque d'Amiens. 
Pedler Emmanuel \& Bourbonnaud David (2002b). « La programmation du Festival. Un pacte de confiance entre l'organisation festivalière et son public ». In ETHIS Emmanuel (dir.), Avignon : le public réinventé. Paris, La Documentation française : 131-159.

PedLeR Emmanuel \& ZeRBIB Olivier (2001). Les Nouvelles Technologies à l'épreuve des bibliothèques. Paris, Bibliothèque publique d'information. Peterson Richard A. \& Simkus Albert (1992). « How Musical Tastes Mark Occupational Status Groups ». In LAMONT Michèle \& FOURNIER Marcel, Cultivating differences : Symbolic Boundaries and the Making of Inequality. Chicago, The University of Chicago Press : 152-168.

Peterson Richard A. (1992). « Understanding audience segmentation :

From elite and mass to omnivore and univore ». Poetics, 21(4) : 243-258.

PETERSON Richard A. (1997). « The Rise and Fall of Highbrow Snobbery as a Status Marker ». Poetics, 25(2-3) : 75-92.

Peterson Richard A. \& KeRn Roger M. (1996). « Changing Highbrow Taste : from Snob to Omnivore ». American Sociological Review, 61(5) : 900-907.

PudAL Bernard (1991). « Le populaire à l'encan ». Politix, $13: 53-64$.

RANCIÈRE Jacques (1981). La Nuit des prolétaires. Archives du rêve ouvrier. Paris, Fayard.

RANCIĖRE Jacques (2011). La Leçon d'Althusser. Paris, La Fabrique.

ReVEL Jacques (dir.) (1996). Jeux d'échelles. La micro-analyse à l'expérience. Paris, Gallimard/Seuil.

Robinson Eric E. (1968). The New Polytechnics. The People's Universities. Harmondsworth, Penguin.

RoEDIGER David (1991). The Wages of Whiteness : Race and the Making of the American Working Class. New York, Verso.

SAPIRO Gisèle (2013a). « La carrière internationale de La Distinction ». In COULANGEON Philippe \& DuvAL Julien (dir.), Trente ans après La Distinction de Pierre Bourdieu. Paris, La Découverte : 45-58.

SAPIRO Gisèle (2013b). « Le champ est-il national ? La théorie de la différenciation sociale au prisme de l'histoire globale ». Actes de la recherche en sciences sociales, $200: 70-85$

SCHILLING Heinz (1981). Konfessionskonflikt und Staatsbildung. Eine Fallstudie über das Verhältnis von religiösem und sozialem Wandel in der Früh Neuzeit am Beispiel der Grafschaft Lippe. Gütersloh, Bertelsmann.
ScotT James (2008). La Domination et les arts de la résistance. Fragments du discours subalterne. Traduction française par Olivier Ruchet. Paris Éditions Amsterdam.

Servien Pius (1935). Principes d'esthétique. Problèmes d'art et langage des sciences. Paris, Boivin.

SINGLY François (DE) (1998). «Bourdieu : nom propre d'une entreprise collective ». Le Magazine littéraire, 369 : 39-44.

SUTTON-SMITH Brian (1970). «Psychology of Childlore : The Triviality Barrier ». Western Folklore, 29(1) : 1-8.

TAINE Hyppolite (1858). Essais de critique et d'histoire. Paris, Hachette. VeYne Paul (1971). Comment on écrit l'histoire. Essai d'épistémologie. Paris, Seuil.

VeYne Paul (2008). Foucault. Sa pensée, sa personne. Paris, Albin Michel. WeBER Max (1998) [1921]. Sociologie de la musique. Les fondements rationnels et sociaux de la musique [Die rationalen und soziologischen Grundlagen der Musik, Tübingen, Drei Masken Verlag]. Traduit de l'allemand par Jean Molino et Emmanuel Pedler. Paris, Métailié.

Wimmer Andreas \& GLICK SCHILLER Nina (2002). « Methodological Nationalism and Beyond : Nation-State Building, Migration and the Socia Sciences ». Global Network, 2 : 301-334. 